\title{
Long-Term Follow-Up and Clinico-Histopathological Features of Simpson Grade 1 Surgical Resection of Large Olfactory Groove Meningioma
}

\author{
Mark K. Lyons*, Barry D. Birch, James A. Wilkens and Kay Miller
}

5777 E Mayo Blvd, Phoenix AZ, USA, Mayo Clinic Arizona, USA

\begin{abstract}
Olfactory groove meningiomas can attain substantial size before producing enough symptoms alerting the patient or physician to the possibility of a tumor. The surgical goal is gross total resection in order to reduce the chances of recurrence, however, increased surgical complication rates can be seen with more aggressive resections. The optimal imaging follow-up time following gross total resection of olfactory groove meningiomas is not known. We report a young woman presenting with a three year history of frontal lobe dysfunction, anosmia and bitemporal visual field loss harboring a massive olfactory groove meningioma. She underwent gross total resection of a tumor with unusual neuropathological features potentially worrisome for aggressive behavior. Ten year follow-up with annual imaging has demonstrated no evidence of recurrence. The current literature on olfactory groove meningiomas following Simpson grade 1 resection regarding the various surgical approaches, complication and recurrence rates is reviewed. Unique features of this case suggest that ongoing surveillance may be necessary.
\end{abstract}

Keywords: Olfactory groove meningioma, histopathology, Simpson grade 1 resection, follow-up.

\section{INTRODUCTION}

Olfactory groove meningiomas arise in the midline of the anterior cranial fossa. These tumors can become extremely large before symptoms develop alerting the patient or physician to the detection of the slow growing tumors. The most common presenting symptoms are cognitive changes, headache, anosmia and bitemporal visual field loss [1-5]. Olfactory groove meningiomas tend to depress and displace the optic apparatus posteriorly as they grow as opposed to tuberculum sella meningiomas which arise from beneath the optic nerves and push them superiorly and laterally. Several different surgical approaches are used for resection of these meningiomas depending upon the size and laterality of the tumor [1-7]. The surgical goal is gross total resection of the tumor whenever possible. Resection of a portion of the anterior cranial osseous structures, from which these tumors can arise, may decrease the chances of recurrence. However, invasion of the paranasal mucosa or en plaque extensions of tumor involvement not detectable on preoperative imaging may also play a role in recurrence of these tumors. Large case series of these tumors report complication rates of up to $33 \%$, most commonly being cerebrospinal fluid leaks $[1,3$, $4,7]$. Few patients with gross total resections of large olfactory groove meningiomas have been reported with ten year radiographic follow-up. Stafford et al. found that in primarily gross totally resected intracranial meningiomas, the 10 year recurrence rate was $25 \%$ [8]. The ongoing follow-up period for gross totally resections of meningiomas arising from the anterior cranial floor is not defined. This report discusses the gross total resection of a massive olfactory groove meningioma. It is unique case given the neuropathological features suggestive of potentially aggressive

*Address correspondence to this author at the 5777 E Mayo Blvd, Phoenix AZ, USA, Mayo Clinic Arizona, USA; Tel: 480-614-3616; Fax: 480-6143699; E-mail: lyons.mark2@mayo.edu behavior which include: increased mitotic activity, lack of calcification and necrosis. The literature regarding recurrence rates of olfactory groove meningiomas is reviewed in order to aid in counseling such a patient regarding long-term radiographic follow-up. The clinical and histopathological features of this case are unique and may suggest that ongoing surveillance for potential recurrence is indicated.

\section{CASE REPORT}

We report the case of a 42 year old female who presented with a three year history of progressive memory deficits, bitemporal visual field loss, anosmia and increasing indifference. Her family had not reported any overt seizure symptoms, but she was noted to have increasingly frequent episodes of staring spells. She was initially treated for depression. When her symptoms did not improve she underwent magnetic resonance (MR) imaging of the brain which demonstrated a massive anterior skull base tumor (Fig. 1A-C). Her neurologic exam revealed a bitemporal visual field loss, bilateral papilledema and mild lower extremity weakness. Formal preoperative visual field testing confirmed bitemporal visual field loss. Neuropsychological testing demonstrated deficits in acquisition of new information, attention to visual detail, abstract reasoning abilities and immediate recall of prose material. Fine motor dexterity was significantly impaired in the nondominant hand. The aggregated Wechsler Adult Intelligence Scale-III (WAIS-III) is based upon the original intelligence scale first published in 1939 where intelligence is defined as a person's ability to adapt and solve problems, thus viewing intelligence in terms of performance rather than capacity [9]. The study utilizes seven verbal scales and seven performance scales. The verbal, performance and full scales scores are converted to an intelligence quotient (IQ) score with normative mean of 100 and standard deviation of 15. Scores of 90-109 are considered average. Our patient's preoperative WAIS-III scores yielded a pro- 


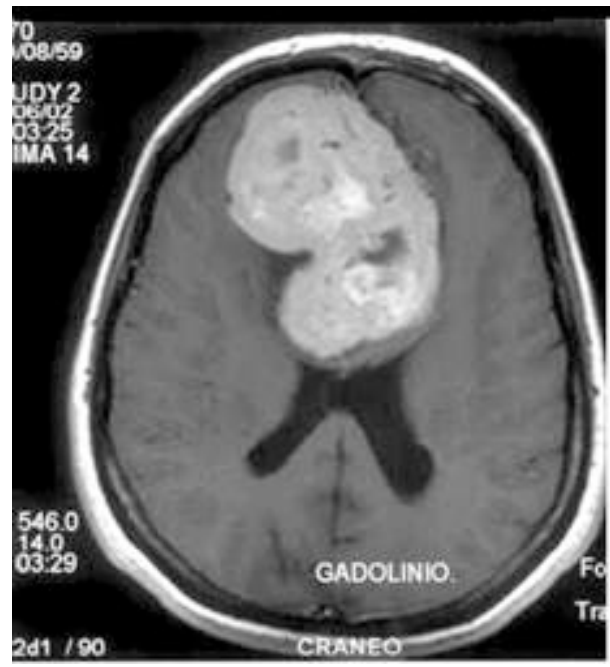

$\mathbf{A}$

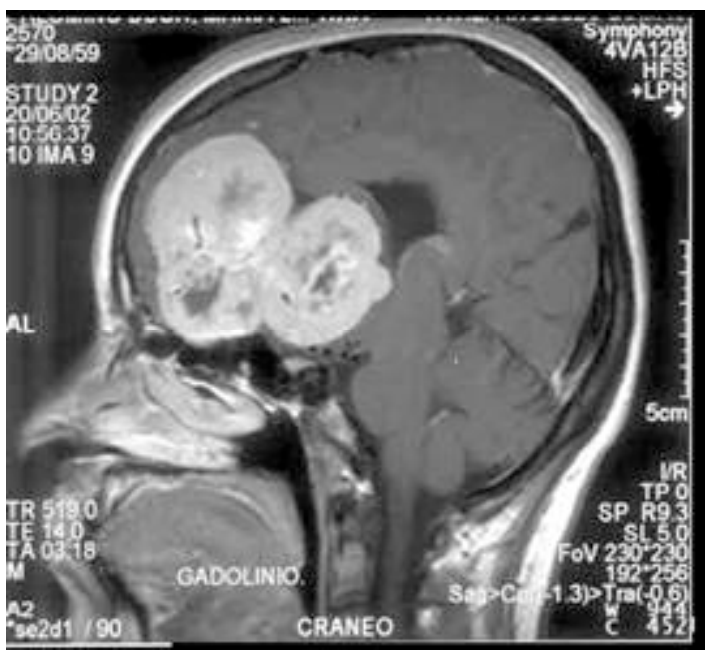

B

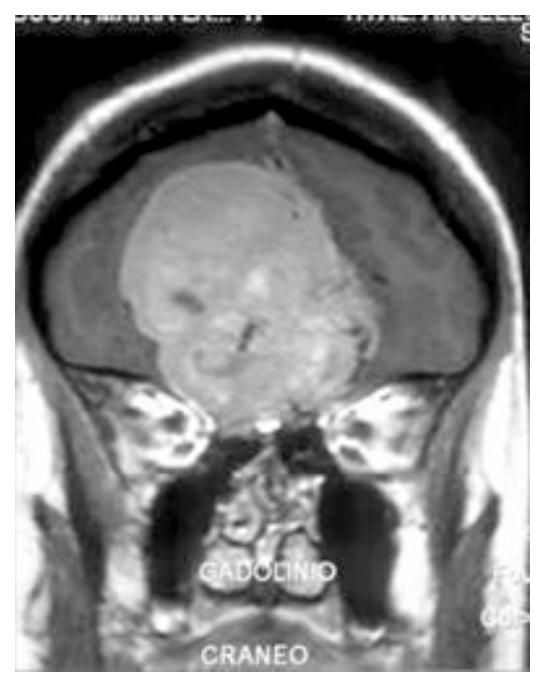

C

Fig. (1). (A-C): Preoperative axial, sagittal and coronal T-1 weighted gadolinium enhanced MR demonstrating massive olfactory groove meningioma.

rated verbal IQ score of 92, performance IQ score of 90 and full scale IQ score of 91. These scores were interpreted by the examiner to be significantly below the anticipated scores given that she had completed a four year college degree. An electroencephalogram revealed a generalized dysrhythmia grade II without epileptiform discharges.

Following embolization of the external carotid artery feeders to the tumor, the patient underwent a bifrontal craniotomy and gross total resection of the olfactory groove meningioma (Simpson grade 1) [10]. The skull base dura and bone were resected. The majority of the vascular supply arose from the ethmoidal arteries and branches from the anterior cerebral arteries. The pathology revealed a mitotically active atypical meningioma with necrosis. There were $4 \mathrm{mi}-$ toses per high powered field. Formal neuropathological interpretation concluded that due to the unusual mitotic activity and necrosis of the tumor it was considered rare for this location. The following additional stains were performed: CD34: positive; S-100: negative; EMA: negative; BCL2: positive; CD99: positive; SMA; negative. These features would be consistent with an atypical meningioma [11]. Five days postoperatively, the patient developed an acute hemorrhage in the tumor resection cavity requiring surgical evacuation. She recovered well from that but did require repair of delayed cerebrospinal fluid leak through the right ethmoid cranial defect ten days later. This was accomplished with harvesting of a vascularized pericranial graft reinforced with fascia lata and free muscle grafts oversewn into the right ethmoidal cranial defect. The Scales of Cognitive Ability for Traumatic Brain Injury (SCATBI) is used for initial postoperative cognitive assessment at our institution. This testing scale measures twelve areas of perception and discrimination ability, three areas of orientation and six areas of organization processing. This testing assessment six weeks postoperatively demonstrated marked improvement in all areas of her preoperative deficits as correlated to the preoperative WAIS-III scores. At follow-up four months postoperatively, her bitemporal visual field loss improved significantly confirmed on formal postoperative visual field testing. The anosmia remained. Repeat electroencephalogra- 


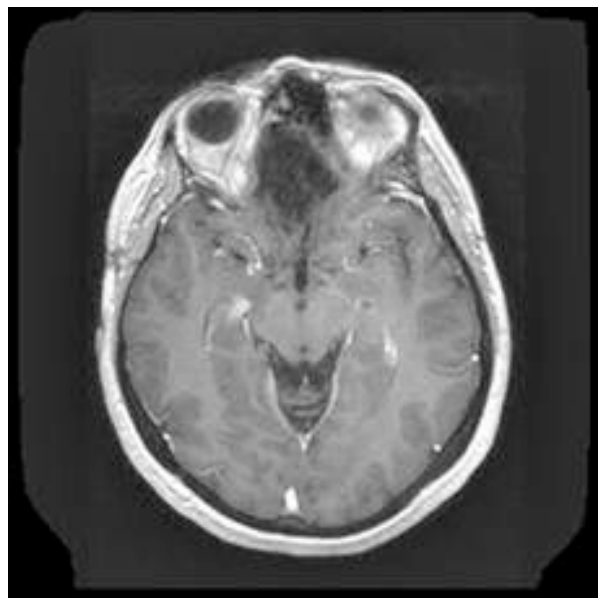

A

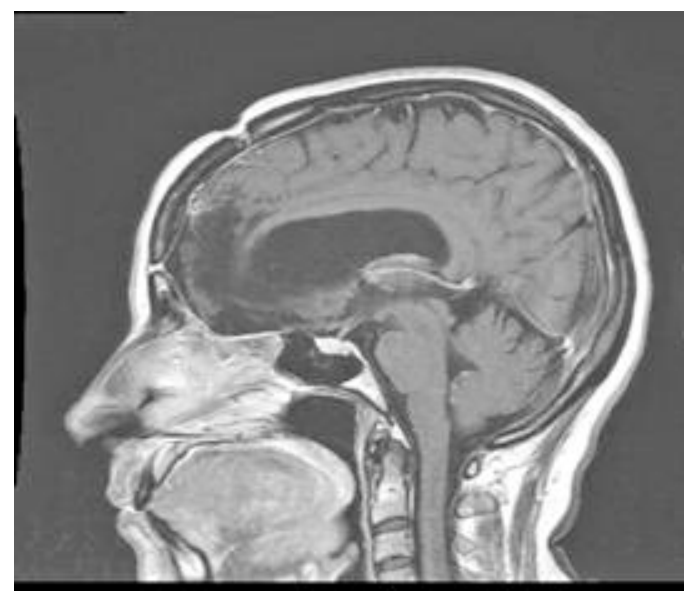

B

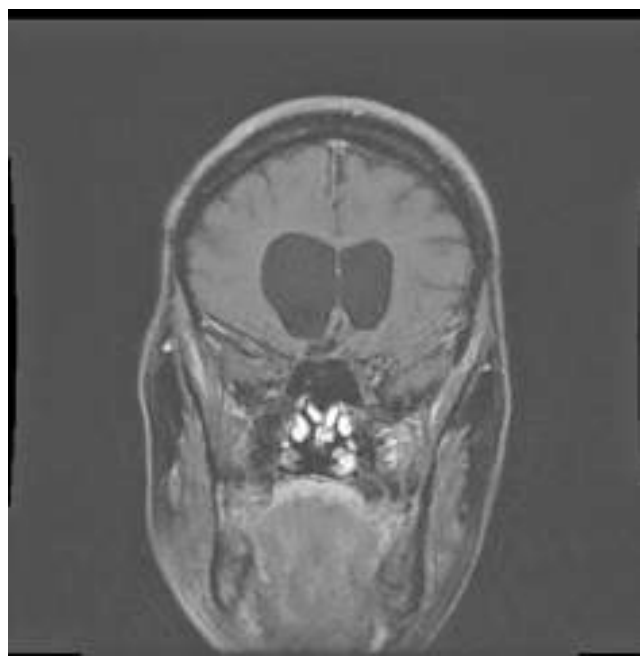

C

Fig. (2). (A-C): Ten year postoperative axial, sagittal and coronal T-1 weighted gadolinium enhanced MR demonstrating postoperative changes of encephalomalacia with some ex-vacuo dilatation of the frontal horns of the lateral ventricles. No evidence of residual or recurrent tumor.

phy six months postoperatively showed mild dysrhythmia grade I without epileptogenic activity. She did not receive postoperative radiation therapy. Aside from her preoperative anosmia and improved bitemporal visual field cut, she has no neurologic deficits. She has undergone annual postoperative MR scans for ten years which have all demonstrated no evidence of tumor recurrence (Fig. 2A-C).

\section{DISCUSSION}

Olfactory groove meningiomas primarily arise from the cribiform plate of the ethmoid bone [3, 7]. These tumors present initially with anosmia, headache, cognitive decline and visual loss [1,12-14]. Larger tumors may produce motor deficits, aphasia and seizures $[3,4,6,15]$. These tumors can, as in our case, become extremely large as symptoms can be subtle and mistaken for other conditions such as depression. Several different surgical approaches can be used for resection of olfactory groove meningiomas [1, 3-5, 7]. The anterior subfrontal approach via a bifrontal craniotomy is most commonly used for large midline tumors. This does require ligation of the anterior superior sagittal sinus and frontal lobe retraction. Lumbar cerebrospinal fluid drainage, neuroanes- thesia techniques and dehydrating agents are helpful in reducing the retraction effect on the already compromised frontal lobes. Unilateral subfrontal, fronto-orbital and subcranial approaches have all been reported in achieving successful gross total resections of olfactory groove meningiomas. The pterional approach requires less brain retraction and can be done without ligating the superior sagittal sinus.

The optimal follow-up time for olfactory groove meningiomas is not yet defined. Several series have been published on the tumors with long term recurrences reported well beyond 10 years following Simpson 1 or 2 grade resections (Table 1). Given the histopathological features of atypia in our case, ongoing surveillance would seem appropriate to at least 12 to 15 years postoperatively. The series of 80 patients surgically treated for olfactory groove meningiomas by Spektor and co-workers combined multiple operative approaches depending upon the tumor size, location and extension of disease [4]. A Simpson grade 1 resection was performed in $90 \%$ of the patients. Only two of the eight patients with subtotal resections were found to have radiographic progression of their tumors [4]. They reported no 
Table 1. Major Series of Olfactory Groove Meningiomas and Reported Postoperative Recurrence Rates

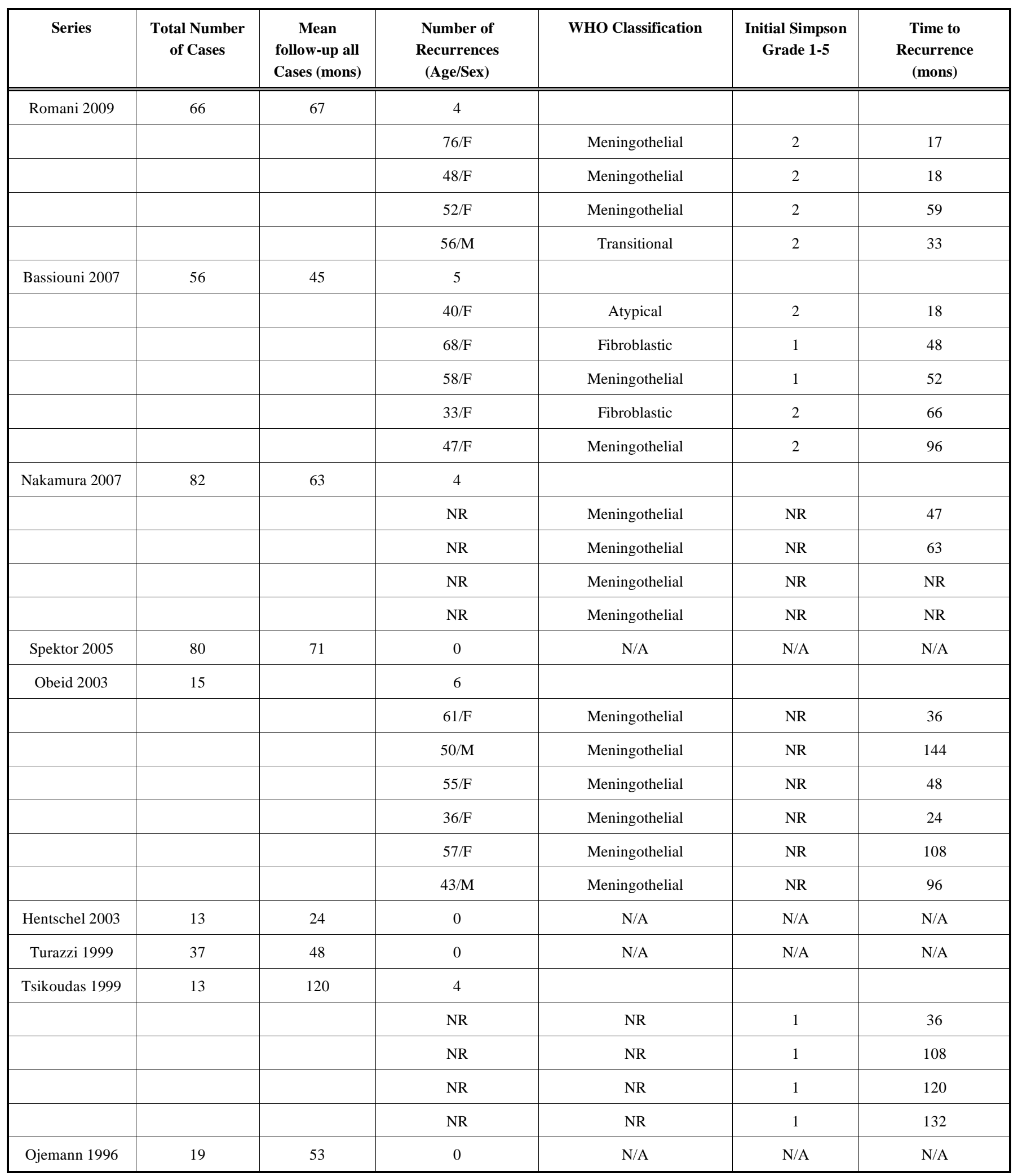

WHO = World Health Organization; N/R = not reported; N/A = not applicable; mons = months.

recurrences in the 72 patients with a mean follow-up of 5.8 years. Surgery related complications occurred in $31 \%$ of the patients, most commonly being cerebrospinal fluid leaks. Bassiouni and colleagues reported their experience in surgi- cal treatment of olfactory groove meningiomas in 56 patients [1]. The bifrontal craniotomy was most commonly used, followed by the pterional and supraorbital approaches. The lateral supraorbital approach is a modification of the classic 
pterional approach. The size and degree of laterality of the tumor impacted the surgical approach utilized. They reported excellent results with only five recurrences requiring reoperation. Two of the five patients with recurrences at 48 and 52 months initially had undergone a Simpson grade 1 resection. The only patient with an atypical meningioma (similar to our patient), who underwent a Simpson grade 2 resection, developed a recurrence at 18 months postoperatively. These results would support the potential need for long term surveillance in such tumors due primarily to the histopathology, despite a Simpson grade 1 resection. Romani and co-workers report on their series of 66 patients undergoing resection of olfactory groove meningiomas utilizing this approach [3]. The patient is rotated approximately 20 to 30 degrees, tilted laterally and the neck flexed to permit optimal visualization of the anterior cranial floor. A small craniotomy of approximately 3 centimeters centered over the pterion was performed. The authors reported overall good results with this approach, including tumor of over six centimeters [3]. However, they reported postoperative complications in $33 \%$ of the patients with $15 \%$ of the patients neurologically worse postoperatively. Although tumor size was not found to be a statistically significant independent risk factor, the authors point out that all of the patients who had no improvement or were worse postoperatively had medium to large tumors [3]. This approach in the hands of very experienced surgeons, such as the senior author of this report [3], can be very effective, but may not be optimal for the large sized tumors. Endoscopic approaches have been reported where bilateral maxillary antrostomies and spheno-ethmoidectomies are performed. This approach also requires bilateral frontal trephines and resection of the floor of the frontal sinus [5]. An advantage of this approach is minimal retraction on the frontal lobes. Webb-Meyers and colleagues have reported a gross total resection of a large olfactory groove meningioma in a 46 year old man who presented with visual loss, anosmia progressive neurocognitive decline via the endoscopic approach with excellent results [5].

Several papers over the past few decades have attempted to analyze and develop predictive models of meningioma growth patterns. The report by Stafford et al. reviewed 581 patients with surgically treated meningiomas and found the 10 year recurrence rate to be $25 \%$ in those patients undergoing a gross total resection and $61 \%$ in those patients with less than a gross total resection [8]. Factors that were identified as associated with tumor recurrence were less than gross total resection, involvement of the anterior visual pathway, age less than 40 years and increased mitotic activity [8]. The pathologic features of the tumor in our case were consistent with an atypical meningioma. The MIB-1 labeling index is often used as a predictor of aggressiveness and recurrence in astrocytomas, but infrequently reported in meningiomas. Ho and colleagues found that the histopathology and MIB-1 labeling index were useful predictors of tumor recurrence in atypical meningiomas [16]. They noted the recurrence rate at 10 years postoperatively in 52 patients treated for meningiomas resected in various intracranial locations was dramatically higher in patients with MIB-1 labeling indexes of greater than 10 ( 0 vs. 97\%) [16]. Although our patient did not have MIB-1 labeling performed on her tumor, the increased mitotic activity and necrosis would suggest an increased risk of potential recurrence. The report by Nakasu and co-workers in their study of 31 meningiomas in 20 patients essentially found that atypical meningiomas grew exponentially and those with calcification grew linearly or not at all [2]. In addition, they did not find any association between tumor size or patient age regarding predictability of tumor growth [2].

The recurrence rates following resection of olfactory groove meningiomas varies from 0 to $41 \%$ [1, 3-5, 7, 10, 11, 13-27]. The report by Ojemann found no recurrences in their series of 19 patients with a mean follow-up of 4.4 years [21]. Similarly, other series have reported no evidence of radiographic recurrence, albeit with shorter follow-up times [26, 27]. Two of the five patients with tumor recurrence in the Bassiouni series had a Simpson grade 1 resection [1]. However, both patients were over the age of 40, had a bifrontal approach and no evidence of increased mitotic activity. None of the patients in the Spektor series with Simpson grade 1 resection have had tumor recurrence, although the mean follow-up was slightly less than six years. Tiskoudas and coworkers reported four case of recurrent tumor following Simpson grade 1 resections at 3, 9, 10 and 11 years following the initial resection [24].

\section{CONCLUSION}

Our patient presented at age 42 with a massive tumor involving the visual pathways. The tumor was non-calcified and had histopathologically identified increased mitotic activity and necrosis. These factors may suggest that despite a Simpson grade 1 tumor resection and 10 year follow-up without evidence of recurrence,. continued MR monitoring for 12-15 years postoperatively would seem appropriate in a case with these features.

\section{REFERENCES}

[1] Bassiouni H, Asgari S, Stolke D. Olfactory groove meningiomas: functional outcome in a series treated microsurgically. Acta Neurochir 2001; 149: 109-21.

[2] Nakasu S, Fukami T, Nakajima M, et al. Growth pattern changes of meningiomas: long-term analysis. Neurosurgery 2005; 56(5): 94655.

[3] Romani R, Lehecka M, Gaal E, et al. Lateral supraorbital approach applied to olfactory groove meningiomas: experience with 66 consecutive patients. Neurosurgery 2009; 65(1): 39-53.

[4] Spektor S, Valarezo J, Fliss DM, et al. Olfactory groove meningiomas from neurosurgical and ear, nose, and throat perspectives: approaches, techniques, and outcomes. Operative Neurosurg 2005; 57(4): 268-80.

[5] Webb-Meyers R, Wormald PJ, Brophy B. An endoscopic endonasal technique for resection of olfactory groove meningioma. $\mathrm{J}$ Clin Neurosci 2008; 15: 451-5.

[6] Mehrazin M, Mirfalah R. Early post operative visual outcome in microsurgically treated suprasellar meningiomas predict long-term visual outcome. Turkish Neurosurg 2008; 18(4): 380-6.

[7] Rubin G, Ben David U, Gornish, et al. Meningiomas of the anterior cranial fossa floor. Review of 67 cases. Acta Neurochir (Wein) 1994; 129: 26-30.

[8] Stafford SL, Perry A, Suman VJ, et al. Primarily resected meningiomas: outcome and prognostic factors in 581 Mayo Clinic patients, 1978 through 1988. Mayo Clin Proc 1998; 73: 936-42.

[9] Wechsler D. Wechsler Adult Intelligence Scale-Third Edition. San Antonio TX: The Psychological Corporation 1997.

[10] Simpson D. The recurrence of intracranial meningiomas after surgical treatment. J Neurol Neurosurg Psychiatry 1957; 20: 22-39.

[11] Riemenschneider MJ, Perry A, Reifenberger G. Histological classification and molecular genetics of meningiomas. Lancet Neurol 2006; 5: 1045-54.

[12] Bakay L, Cares HL. Olfactory groove meningiomas. Report on a series of twenty-five cases. Acta Neurochir (Wein) 1972; 26: 1-12. 
[13] Snyder WE, Shah MV, Weisberger EC, et al. Presentation and patterns of late recurrence of olfactory groove meningiomas. Skull Base Surg 2000; 10: 131-9.

[14] Welge-Luessen A, Temmel A, Quint C, et al. Olfactory function in patients with olfactory groove meningioma. J Neurol Neurosurg Psychiatry 2001; 70: 218-21.

[15] Gerber M, Vishteh AG, Spetzler RF. Return of olfaction after gross total resection of an olfactory groove meningioma: case report. Skull Base Surg 1998; 8: 229-31.

[16] Ho DM, Hsu CY, Ting LT, et al. Histopathology and MIB-1 labeling index predicted recurrence of meningiomas: a proposal of diagnostic criteria for patients with atypical meningiomas. Cancer 2002; 94: 1538-47.

[17] Nakao N, Ohkawa T, Miki J, et al. Surgical treatment and outcome of skull base meningiomas with extracranial extensions. Clin Neurol Neurosurg 2010; 112: 40-6.

[18] Chan RC, Thompson GB. Morbidity, mortality, and quality of life following surgery for intracranial meningiomas: a retrospective study in 257 cases. J Neurosurg 1984; 60: 52-60.

[19] El Gindi S. Olfactory groove meningiomas: surgical techniques and pitfalls. Surg Neurol 2000; 54: 415-7.
[20] Obeid F, Al-Mefty O. Recurrence of olfactory groove meningiomas. Neurosurgery 2003; 53: 534-43.

[21] Ojemann RG. Supratentorial meningiomas: clinical features and surgical management. In: Wilkins RH, Rengachary SS, eds. Neurosurgery, New York, NY: McGraw-Hill 1996; Vol. 1: pp. 873-90.

[22] Nakamura M, Struck M, Roser F, et al. Olfactory groove meningiomas: clinical outcome and recurrence rates after tumor removal through the frontolateral and bifrontal approach. Neurosurgery $2007 ; 60(5): 844-52$.

[23] Obeid F, Al-Mefty O. Recurrence of olfactory groove meningiomas. Neurosurgery 2003; 53(3): 534-43.

[24] Tiskoudas A, Martin-Hirsch DP. Olfactory groove meningiomas. Clin Otolaryngol 1999; 24: 507-9.

[25] Mirimanoff RO, Dosoretz DE, Linggood RM, et al. Meningioma: analysis of recurrence and progression following neurosurgical resection. J Neurosurg 1985; 62: 18-24.

[26] Hentschel SJ, DeMonte F. Olfactory groove meningiomas. Neurosurg Focus 2003; 14(6): 1-5.

[27] Turazzi S, Cristofori L, Gambin R, et al. The pterional approach for the microsurgical removal of olfactory groove meningiomas. Neurosurgery 1999; 45: 821-6.

(C) Lyons et al.; Licensee Bentham Open.

This is an open access article licensed under the terms of the Creative Commons Attribution Non-Commercial License (http://creativecommons.org/licenses/by-nc/3.0/) which permits unrestricted, non-commercial use, distribution and reproduction in any medium, provided the work is properly cited. 